\title{
INTEGRATING THE ANALYTIC NETWORK PROCESS AND THE BALANCED SCORECARD FOR STRATEGIC IT OUTSOURCING DECISION MAKING
}

\author{
By Youxu Tjader*, Jennifer Shang, Luis Vargas, Jerry May \\ The Joseph M. Katz Graduate School of Business \\ University of Pittsburgh, Pittsburgh, PA 15260 \\ Shang@katz.pitt.edu
}

\begin{abstract}
In outsourcing, management seeks to achieve costs savings, operational efficiency, customer satisfaction, and/or company growth. We integrate the ANP with the perspectives in Balanced Scorecard (BSC) for IT outsourcing decision making. The proposed BSC-ANP model helps evaluate the impact of decision on firm performance and confirms the existence of indicator interactions.
\end{abstract}

Keywords: Outsourcing, ANP, BSC, Strategic Decision

\section{Introduction}

Beginning with Kodak's 1989 contract with IBM (Applegate et al. 1990), IT outsourcing has grown steadily as a strategic IT management option. During this period, the pressure of globalization, rapid technological evolution, and the necessity for cost reduction have compelled companies to turn to outsourcing for their information technology needs. In the early 1990s, the two primary objectives for IT outsourcing were cost savings and technical efficiency. Today, the number of outsourcing objectives has increased along with their significance to the firm and, as a result, outsourcing has become a strategic option for firms seeking to improve their overall business performance. In the current business environment, outsourcing objectives are not only economic, but also strategic (e.g., aligning IT with corporate objectives), technological (e.g., standardizing hardware, software and business processes), and social (e.g., improving user satisfaction).

Notwithstanding the potential benefits, outsourcing also entails a number of costs, particularly those related to identifying, transitioning to, and managing the outsourcing vendor. Additional costs can occur due to the introduction of significant business risks which, if not managed properly, can lead to negative outcomes. Risk factors that can put the client at risk include specialization of the product and/or vendor, uncertainty of the business environment, interdependence between client and vendor business processes, and the level of client and vendor expertise with both the IT operation and outsourcing in general. In light of these elements of risk, a successful firm would understand and prioritize its objectives, set specific and obtainable goals, select the right vendor(s), and negotiate an enforceable contract with vendor(s) (Domberger, 1998) (Corbett, 2004). In daily operations, the firm would engage in effective communications and monitoring in pursuit of successful vendor relationships management.

Toward this end, management requires a structured approach that considers the elements of decision making involved in the outsourcing process: i.e., the objectives sought through outsourcing, the associated benefits and costs, and the set of criteria for making outsourcing decisions in specific situations. The Balanced Scorecard (BSC) method provides these elements within a framework that assesses strategic performance within four generic management perspectives. The Analytic Network Process (ANP) in turn provides a structure and process that guide the decision maker in weighing the 
various criteria and choosing actions intended to achieve the stated objectives. In an outsourcing decision problem, because the elements and sub-elements of the BSC are inherently interdependent and therefore not strictly hierarchical, the network approach provided by the ANP is preferred.

In this paper we present a framework that applies an ANP model within the context of the BSC, to provide an integrated approach to decision making in an outsourcing environment. We begin with a discussion of the BSC, including its genesis, objectives, and basic components, followed by an overview of AHP and ANP. We then discuss outsourcing from a decision theoretic perspective, describing the role of ANP as a model for multicriteria decision-making. Having established the theoretical justification for the use of BSC and ANP in an outsourcing decision, we describe the development of the model as well as the subsequent application of the model to the decision process. We also provide a case example demonstrating the functionality of the model.

\section{Literature review}

\subsection{The balanced scorecard}

As organizations attempt to generate continued growth for future economic value creation, existing unidimensional financial performance measures have become increasingly inadequate and irrelevant (Francis \& Shipper, 1999). To address this problem and provide a more comprehensive measurement of corporate performance, Kaplan and Norton developed the multi-dimensional Balanced Scorecard (BSC), which considers other quantitative and qualitative measures in addition to the traditional financial measures. (Hooks, Kaplan \& Schultz, 1994) The BSC was proposed as a way for firms to consider a structured but manageable set of objectives in strategic decision making, and it has been widely adopted as a performance measurement framework (Rigby, 2001; Cobbold \& Lawrie, 2002a). Since its original introduction, the popularity of BSC has increased steadily, and is now used by more than $60 \%$ the fortune 1000 companies. (Marr \& Neely, 2003)

The BSC incorporates a structure intended to make decision making more robust without making the evaluation of alternatives overly complex and unwieldy. The BSC reflects a balance between short and long-term objectives, financial and non-financial measures, lagging and leading indicators, and external and internal measures. It differs from typical performance measurement systems through its emphasis on linking and aligning multiple measures to strategic objectives. The BSC is a method for conceptualizing the strategic alignment between business goals and specific tactics, considering an organization from four perspectives: financial measures, customer satisfaction, internal operations, and company learning and growth.

By identifying the indicators for each specific goal under each perspective, the BSC permits the organization of the indicators (measures) within the four perspectives and also indicates the interactions among them (as denoted by the arrows between perspectives in Figure 1). To implement a BSC framework, management must establish the strengths of all relationships and determine their relative importance.

\subsection{The analytic network process (ANP)}

ANP can improve communication and resolve conflicts, help diffuse responsibility, and assist decisionmakers in understanding other members' viewpoints. These characteristics are attractive when a good decision calls for actions that may not be well-liked, such as outsourcing. The ANP is capable of evaluating a wide range of criteria, including tangible and intangible factors that have bearing on the outcome. The ANP allows for complex interactions and influences among the various components of the decision problem, thus making it a better choice for studying more complex decision problems 


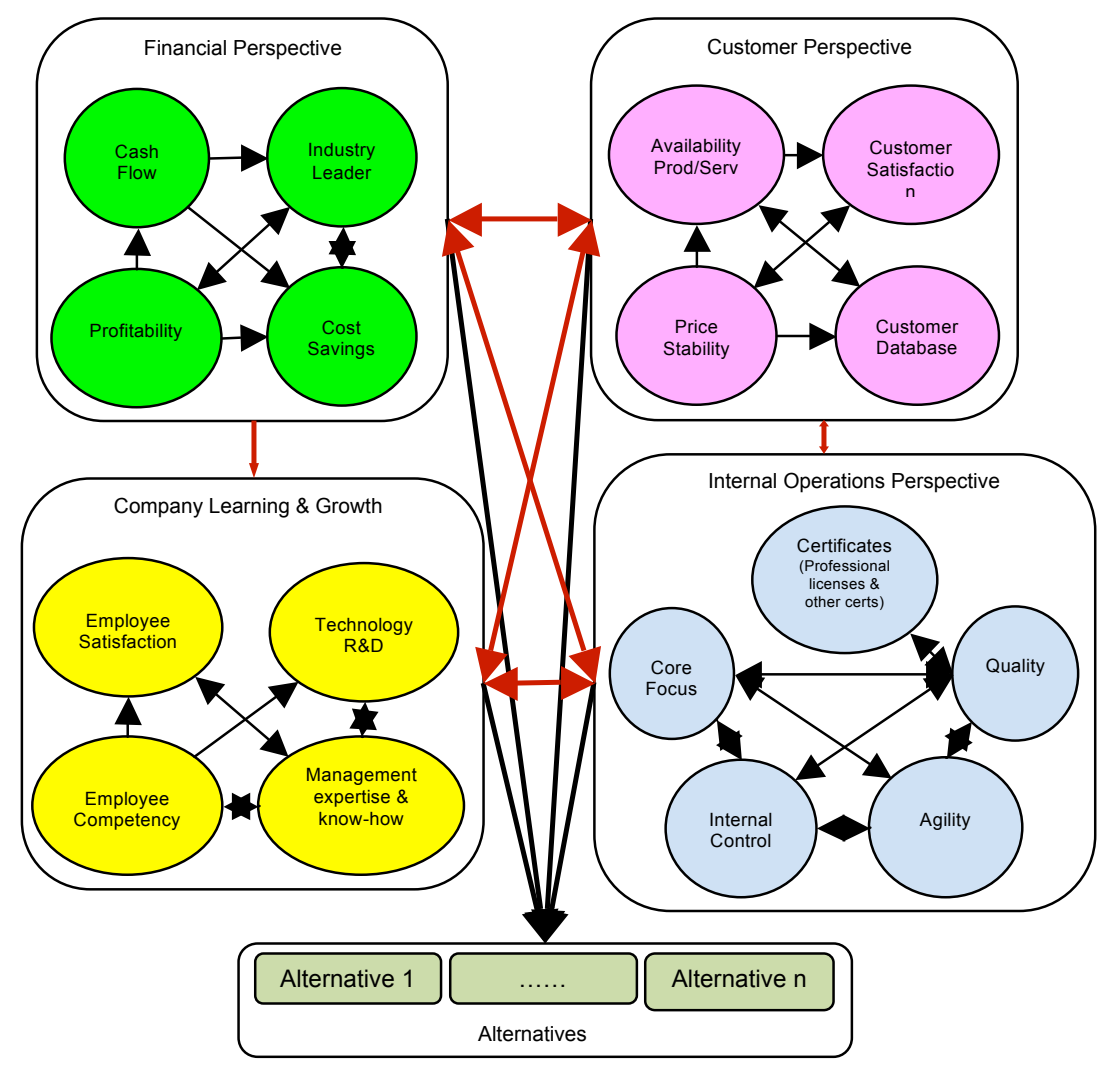

Figure 1. Strategic decision framework

(Saaty \& Ozdemir, 2004). ANP brings all of the decision objectives, criteria, alternatives and actors (such as decision makers, stakeholder, and influencers) into a single unified framework, and it facilitates interaction and feedback of elements (alternatives, criteria and actors) within groups (inner dependence) and between groups (outer dependence) (Saaty, 2001). Most complex real-world decision problems have numerous inter-dependent elements that can be captured and processed utilizing the feedback and interaction capabilities of an ANP model. In this regard, ANP has been applied to transportation project selection (Shang, Tjader \& Ding, 2004), policy decisions (Saaty, 2005, Tjader, Shang \& Vargas, 2009) supply chain management system analysis (Meade \& Sarkis, 1998, Nakagawa \& Sekitani, 2004), etc. For more examples of ANP applications, see Saaty and Vargas (2006).

To derive the global priorities of the criteria using ANP, it is necessary first to pairwise compare the criteria with respect to the node representing their category and to all other criteria with which they interact or on which they have influence. Next, the principal right eigenvector of each comparison matrix is computed to obtain the local priority of every criterion (Saaty, 1980). In the last step, a super-matrix consisting of all the local-limiting matrices is formed for overall criteria prioritization and alternative ranking. The weighted supermatrix is taken to the limit for the final results.

The strategic alternatives are pairwise compared for each criterion. For example: 'With respect to a specific criterion, is Alternative $\mathrm{X}$ better than Alternative Y. If so, then how much better?' An inverse value is chosen if, under the specified criterion, Alternative $\mathrm{Y}$ is better than Alternative $\mathrm{X}$. Similar to criteria rankings, each set of comparison matrices is used to calculate the local rankings of the alternatives. The local rankings of the alternatives are included in the supermatrix for final calculation or synthesis. The composite scores of the alternatives are the overall rankings of the alternatives, and are summarized as the final synthesized alternative rankings. 


\subsection{The outsourcing decision}

At the broadest conceptual level, the outsourcing decision distills into three basic strategies as defined by Lacity and Willcocks (2000). These strategies are Insourcing, Outsourcing, and Selective Outsourcing (SelectOut).

- Insourcing. The company retains the management and provision of more than $80 \%$ of the IT budget internally. Insourcing used to be the preferred option for large corporations, although some followed Kodak and outsourced the majority of their IT departments starting in the early 1990s.

- Outsourcing. A decision to transfer IT assets, leases, staff, and management responsibility for delivery of IT services from an internal IT function to an external IT provider which represents more than $80 \%$ of the IT budget.

- Selective outsourcing (SelectOut). Selective outsourcing is "to source selected IT function from external provider(s) while still providing between $20 \%$ and $80 \%$ of the IT budget internally." For companies that emphasize the safety and security of their customer databases, selective outsourcing is often the practice of choice. Cullen and Willcocks (Cullen \& Willcocks, 2003) find selective outsourcing tends to have lower risk than more complete outsourcing.

\subsection{Multicriteria decision models}

AHP has been suggested by a number of researchers for outsourcing decision making, but none have considered the full range of perspectives and indicators included in the BSC. Chen et al. (2007) and Lockachari and Mohanarangan (2001) did not consider strategic criteria because the alternatives they evaluated were the operational-level options: i.e., specific IT outsourcing projects and software development options respectively. In Udo (2001), Yang and Huang (2004), and Yang et al. (2004) the customer perspective, and the learning and growth perspective were considered when selecting the determinants (decision criteria). But Udo (2001) and Yang and Huang (2004) only included a small number of evaluation criteria. Yang et al. (2004) presented a basic AHP model to make a business process outsourcing (BPO) decision. Often the criteria in the model were not complete and the model was still rudimentary. In particular, they did not consider the interaction of criteria.

In this regard, a key feature of the BSC is its ability to consider the interactions (or influences) of indicators on other indicators, and the interactions and influences of perspectives on other perspectives. Kaplan and Norton (1994), Campbell et.al (2002) and Cobbold \& Lawrie (2002b) have demonstrated that including interrelationships among indicators and perspectives while developing BSC metrics is essential. This is because interactions with other indicators can increase or decrease the intensity of an indicator. Thus, not including the interrelationships can compromise the power and accuracy of the BSC framework. In designing a performance measurement system for an organic food company (KVIC) in India, Thakkar et al. (2007) used a BSC model with indicator interactions along with ANP to determine the weights for BSC perspectives. Alternatively, Lee and Kim (2000) proposed an ANP-Goal Programming (GP) framework for the IS project selection problem. They employed a small hypothetical example given by Marc and Wilson (1991) to illustrate the advantages of combining ANP and GP, and they utilized ANP to reflect the interdependencies among criteria and alternatives (candidate projects).

It is important to note the advantages of the combined BSC-ANP approach relative to either a BSC-GP approach or a standalone AHP or ANP approach. The major disadvantage in using GP is that in a goal programming model the decision-maker must specify both the goals and their relative importance (priority). In the formulation of a GP outsourcing model, it may be difficult to determine directly the level of attainment for each goal and the penalty weights for over-attainment or under-attainment. 
Furthermore, formulating a GP model that addresses all aspects of a BSC with 17 criteria, some qualitative and all interacting with each other in possibly complex ways, would likely place an unreasonable burden on a decision maker. Likewise, in using the ANP/AHP alone without the aid of BSC, the decision maker might develop a model with an incomplete set of decision criteria (possibly missing some important ones, as in Stausberg et al. (2001), Dong et al. (2004), and/or with some of the criteria being repeated. The inclusion of BSC provides a framework to ensure that all important criteria are examined and relevant ones are included in our outsourcing decision model. ANP provides a convenient means of including BSC indicator interactions and prioritizing the BSC indicators.

\section{Elements of BSC and ANP in the outsourcing decision}

The relevance of the combined model for outsourcing decisions can be illustrated in terms of the various factors and interactions inherent in the outsourcing decision. A framework for the illustration is provided by the four perspectives of the BSC: customer, financial, internal operations, and company learning \& growth.

\subsection{Customers' perspective}

Due to their technological specialization, IT vendors may directly provide for, or indirectly facilitate, better quality goods or services than an in-house team can. Superior IT vendors can also support a firm's efforts in improving its credibility and image towards it customers, and in gaining the trust of its customers. Furthermore, IT outsourcing could present the possibility for firms to increase business activity and gain market access and business opportunities. Those considerations are particularly meaningful during the periods when funding, internal or external, is not available to support an expansion opportunity.

Successful outsourcing has the potential to bring tremendous value to customers, employees and shareholders. But outsourcing often opens up a firm's customer database to its vendor, which increases the risk of the firm's customer information being compromised. Furthermore, if a company's IT vendor is inexperienced, outsourcing could cause customer dissatisfaction. Therefore, prudent vendor selection, careful contract negotiation, and vigilant monitoring of daily operations are critical in order to minimize such risk.

\subsection{Financial perspective}

Outsourcing allows firms to free up internal manpower and resources, and to reduce the need for management oversight. As a consequence of the provider's economies of scale, IT outsourcing may result in a cost reduction. Firms seeking a cash infusion may indirectly increase capital by cutting down investments in fixed assets, and turning fixed costs into variable costs, which, in turn, affect the cash flow of the company.

By taking advantage of external suppliers' lower costs, a firm can reduce its own "Fixed cost", "Variable Cost" and "Human cost." Due to reduced capital expenditures, firms may free up funds, make capital available for other purposes, and achieve greater financial flexibility. A better outsourcing strategy can increase a firm's competitive advantage, and increase in market share. A larger market share normally implies better financial performance, which moves the company to a better financial position, from which it may become an industry leader.

The last financial indicator is the Profitability of the firm. Even though cost savings usually lead to greater profitability, there is a potential risk of incurring transition costs, and project/vendor management costs, which can more than offset the savings from outsourcing, resulting in a net profit decrease. 


\subsection{Internal operations perspective}

A firm may consider outsourcing non-core activities, in order to excel at core business processes, improve company focus, and increase operating efficiency. By minimizing routine maintenance and nonessential infrastructure in IT, a firm can apply its internal resources to meet changing business conditions, accelerate reengineering, and improve response time. Experienced and competent vendors make client firms agile, responsive to market needs, and technology smart. Client firms become more flexible, because they can obtain extra capacity and new technologies whenever they are in need. High flexibility enables a firm to react quickly to changing business environment and market situations. However, a company may lose control over those activities that are outsourced. Therefore, prudent vendor(s) selection, careful coordination, integration, and supervision are necessary. Finally, partnering with outsourcing vendors helps a firm to obtain technologies, to develop world-class capabilities, and to share operational risks, resulting in an improved infrastructure and broadened operational reach.

\subsection{Company learning and growth - innovation and employee development}

Management expertise, employee competency, and the organization's effectiveness are parts of the intangible assets that are critical for the success of a knowledge-based company, as well as being an integral part of the company's learning and growth. For socially responsible employers, outsourcing frees up human resources and provides them with the opportunity to re-train their employees in new skills and technologies. Learning cutting-edge technologies brings employees closer to formulating new concepts and to generating novel ideas. However, outsourcing may also make employees anxious and insecure, which may deplete a firm's skill-base, and reduce learning and growth potential. The pressure of creating greater immediate profit can also push the management to lower re-training budgets, which contributes to additional IT workers being laid off and the dissatisfaction of those in need of re-training.

By tapping into providers' world-class IT capabilities, firms can reallocate more resources to focus on organizational effectiveness, management expertise, and technology research and development. Therefore, well planned resource allocation post-outsourcing could make a company more capable in terms of innovation and $\mathrm{R} \& \mathrm{D}$, while inferior resource allocation will do the opposite. Thus, the choice of outsourcing and subsequent strategy may either enhance or weaken the technology research and development for new products and/or services.

\section{A model for combining the balanced scorecard with the ANP}

The BSC-ANP model developed in this study is an analysis network consisting of nodes representing decision criteria and alternatives, and arcs depicting relationships among criteria and alternatives. An arc is present between a pair of nodes only when there is significant interaction (with a two way arrow) or impact from one to the other (with a one way arrow) and vice versa. Figure 1 provides an overview of the framework.

After all the required connections are made, the criteria are pairwise-compared, both within and between clusters. For example, when comparing the criteria within the internal operations cluster with respect to the Profitability criterion in the financial cluster, we capture the relative importance of internal operations criteria when Profitability is concerned. ANP sensitivity analysis may be used to assess the robustness of the final solution. The criteria used for evaluating the strategic alternatives are the performance metrics in each of the four BSC perspectives. The overall goal of the proposed model is to derive a numerical score for each of the strategic alternatives. 
Table 1 Summary of related literature

\begin{tabular}{|c|c|c|c|}
\hline & Main Objective & Methodologies & Underlining Theory \\
\hline $\begin{array}{l}\text { K. Hafeez, Y.B. Zhang, } \\
\text { and N. Malak (2002) }\end{array}$ & Firm Capability Evaluation & $\mathrm{AHP}$ & $\begin{array}{l}\text { BSC - firm capabilities are evaluated } \\
\text { under } 6 \text { ( } 3 \text { financial } 3 \text { non-financial) } \\
\text { BSC measures }\end{array}$ \\
\hline $\begin{array}{l}\text { Hong, J-Y., Suh, E-H., } \\
\text { Yoo K-D, Hong, D-G } \\
(2003)\end{array}$ & Evaluating ASPs & $\mathrm{BSC}$ & $\begin{array}{l}\text { BSC - propose a set of multi- } \\
\text { dimensional measurement for } \\
\text { evaluating the ASPs. No mention of } \\
\text { how to quantify the measures }\end{array}$ \\
\hline $\begin{array}{l}\text { K. Hafeez, N. Malak, and } \\
\text { Y.B. Zhang (2007) }\end{array}$ & $\begin{array}{l}\text { Assessing firm competences, } \\
\text { identify core asset }\end{array}$ & AHP & Resource based view of the firm \\
\hline Udo, Godwin (2000) & $\begin{array}{l}\text { Select which IT function to } \\
\text { outsource }\end{array}$ & $\mathrm{AHP}$ & $\mathrm{AHP}$ \\
\hline $\begin{array}{l}\text { Yang, Chyan, Huang, Jen- } \\
\text { Bor }(2000)\end{array}$ & $\begin{array}{l}\text { Select which IT function to } \\
\text { outsource }\end{array}$ & AHP & $\mathrm{AHP}$ \\
\hline $\begin{array}{l}\text { Yang, D-H, Kim S., Nam, } \\
\text { Changi, Min J-W (2007) }\end{array}$ & BP Outsourcing Decision & $\mathrm{AHP}$ & AHP \\
\hline $\begin{array}{l}\text { Chen, J-R., Chou, T-C, } \\
\text { and Lin, Y-C (2007) }\end{array}$ & IT outsourcing project evaluation & AHP & AHP \\
\hline $\begin{array}{l}\text { Lockachari, P, } \\
\text { Mohanarangan, M. ( } \\
\text { 2001) }\end{array}$ & $\begin{array}{l}\text { Select best software development } \\
\text { option }\end{array}$ & AHP & AHP- three alternatives, 18 criteria \\
\hline $\begin{array}{l}\text { Thakkar, Jitesh, } \\
\text { Deshmukh, S.G., Gupta, } \\
\text { A.D., Shanker, Ravi } \\
\text { (2007) }\end{array}$ & $\begin{array}{l}\text { Development of a BSC (Determine } \\
\text { weights of BSC perspectives) }\end{array}$ & $\begin{array}{l}\text { ANP/ISM } \\
\text { (Interpretive } \\
\text { Structural Modeling) }\end{array}$ & $\mathrm{BSC}$ \\
\hline $\begin{array}{l}\text { Bodin, Lawrence, Gordon, } \\
\text { Lawrence, \& Loeb, Martin } \\
(2005)\end{array}$ & $\begin{array}{l}\text { Evaluating information security } \\
\text { investment }\end{array}$ & AHP & AHP \\
\hline $\begin{array}{l}\text { Yoon, Y-K, and Im, Kun } \\
\text { Shim (2005) }\end{array}$ & $\begin{array}{l}\text { Evaluating IT outsourcing } \\
\text { customer satisfaction }\end{array}$ & AHP & AHP \\
\hline $\begin{array}{l}\text { Nam, Kichan, } \\
\text { Rajagopalan, S. (1996) }\end{array}$ & $\begin{array}{l}\text { Investigate the impact of } \\
\text { organizational, environmental \& } \\
\text { economic factors on IS } \\
\text { Outsourcing decisions }\end{array}$ & $\begin{array}{l}\text { Hypotheses } \\
\text { Testing }\end{array}$ & $\begin{array}{l}\text { Transaction Cost Economics (TCE), } \\
\text { Incomplete contracts (IC), and Power } \\
\text { Theory }\end{array}$ \\
\hline $\begin{array}{l}\text { Lee, Jin Woo } \\
\text { Kim, Soung Hie (2000) }\end{array}$ & $\begin{array}{l}\text { Inter dependent IS project } \\
\text { selection }\end{array}$ & ANP & Goal Programming (GP) \\
\hline This paper & $\begin{array}{l}\text { Identify the best IT outsourcing } \\
\text { strategy for a firm; prioritize firm's } \\
\text { IT functions for outsourcing } \\
\text { consideration }\end{array}$ & ANP/AHP & $\mathrm{BSC}$ \\
\hline
\end{tabular}

Table 2 lists 17 performance indicators relevant to the outsourcing decision used in our BSC-ANP model, along with a brief description of each. The clustering of the criteria is based on the four perspectives of BSC. The four squares on top of Figure 1 illustrates the network of the 17 BSC performance indicators. A one-way arrow is placed between node A and node B only when A influences B or vice versa. One-way arrows can also represent subordinate relationship between nodes. A two-way arrow is placed between node $\mathrm{A}$ and node $\mathrm{B}$ when changes in $\mathrm{A}$ affect $\mathrm{B}$, and at the same time, changes in B affect $\mathrm{A}$. In other 


\begin{tabular}{|c|c|c|c|}
\hline \multirow{2}{*}{$\begin{array}{c}\text { BSC } \\
\text { Perspectives }\end{array}$} & \multicolumn{3}{|c|}{ Balanced Scorecard Indicators \& Corresponding ANP Criteria } \\
\hline & Indicator Name & Description & ANP Criteria \\
\hline \multirow{4}{*}{ Customer } & $\begin{array}{l}\text { Availability of } \\
\text { Product/Service }\end{array}$ & Product or service availability to customers & AvailabilityPS \\
\hline & Customer Database & $\begin{array}{l}\text { The firm's customer information database and how well it has been } \\
\text { managed }\end{array}$ & Database \\
\hline & Customer Satisfaction & Customer satisfaction survey results & Satisfaction \\
\hline & Price Stability & Stability of product/service prices to customer & Prices \\
\hline \multirow{4}{*}{ Financial } & Cash Flow & Improved cash flow due to capital infusion & CashFlow \\
\hline & Cost Savings & Cost of sales reduction due to vendor's efficiency and economy of scale & CostSavings \\
\hline & Industry Leadership & Measured by the increased revenue and market share & IndLeader \\
\hline & Profitability & As measured by the firm's ROI and/or EVA & Profitability \\
\hline \multirow{5}{*}{$\begin{array}{l}\text { Internal } \\
\text { Operations }\end{array}$} & Agility & Firm's responsiveness to change - new or changing demand & Agility \\
\hline & Certifications & Professional licenses, and quality or environmental certifications & Certifications \\
\hline & Core Focus & Firm's success in focusing on its core business processes & CoreFocus \\
\hline & Internal Control & Firm's ability to control all its business processes and departments & InternalControl \\
\hline & Quality & The quality improvement of firm's products/services & Quality \\
\hline \multirow{4}{*}{$\begin{array}{l}\text { Company } \\
\text { Learning \& } \\
\text { Growth }\end{array}$} & Employee Competency & The competency of the firm's employees & EmpCompetency \\
\hline & Employee Satisfaction & $\begin{array}{l}\text { The satisfaction level of employees based on salary and/or promotions } \\
\text { within }\end{array}$ & EmpSatisfaction \\
\hline & Management Knowhow & $\begin{array}{l}\text { Management expertise and other know-how to facilitate innovation and } \\
\text { learning }\end{array}$ & MgtKnowHow \\
\hline & Technology RD & Technology research and development effort and success & TechRD \\
\hline
\end{tabular}

Table 2 List of relevant BSC performance measurement indicators with descriptions

\begin{tabular}{|l|c|c|c|c|}
\hline \multicolumn{5}{|c|}{$\begin{array}{c}\text { Pairwise comparisons of the criteria within the Financial perspective } \\
\text { cluster with respect to the Financial Node }\end{array}$} \\
\hline & CashFlow & CostSavings & IndLeader & Profitability \\
\hline CashFlow & 1 & $1 / 5$ & $1 / 2$ & $1 / 7$ \\
\hline CostSavings & 5 & 1 & 2 & $1 / 2$ \\
\hline IndLeader & 2 & $1 / 2$ & 1 & $1 / 3$ \\
\hline Profitability & 7 & 2 & 3 & 1 \\
\hline Local Priorities & 0.0671 & 0.2908 & 0.1473 & 0.4948 \\
\hline
\end{tabular}

Table 3 Pairwise comparisons of criteria within the Financial perspective

\begin{tabular}{|l|c|c|c|c|}
\hline \multicolumn{5}{|c|}{$\begin{array}{c}\text { Pairwise comparisons of criteria within the Customers perspective cluster } \\
\text { with respect to the financial criterion Profitability }\end{array}$} \\
\hline & AvailabilityPS & Database & Prices & Satisfaction \\
\hline AvailabilityPS & 1 & 4 & 2 & $1 / 2$ \\
\hline Database & $1 / 4$ & 1 & $1 / 2$ & $1 / 5$ \\
\hline PriceS & $1 / 2$ & 2 & 1 & $1 / 3$ \\
\hline Satisfaction & 2 & 5 & 3 & 1 \\
\hline Local Priorities & 0.2879 & 0.0809 & 0.1539 & 0.4773 \\
\hline
\end{tabular}

Table 4 Pairwise comparisons of criteria within the Customers perspective 


\begin{tabular}{|c|c|c|}
\hline \multicolumn{3}{|c|}{ Criteria Global Priorities } \\
\hline & Criterion Name & Priority \\
\hline \multirow{4}{*}{ Customers } & AvailabilityPS & 0.05695 \\
\hline & Database & 0.03934 \\
\hline & Prices & 0.04269 \\
\hline & Satisfaction & 0.11730 \\
\hline \multirow{4}{*}{ Financial } & CashFlow & 0.01178 \\
\hline & CostSavings & 0.04054 \\
\hline & IndLeader & 0.04076 \\
\hline & Profitability & 0.05031 \\
\hline \multirow{5}{*}{$\begin{array}{c}\text { Internal } \\
\text { Operations }\end{array}$} & Agility & 0.04340 \\
\hline & Certifications & 0.01765 \\
\hline & CoreFocus & 0.04233 \\
\hline & InternalControl & 0.02854 \\
\hline & Quality & 0.04245 \\
\hline \multirow{4}{*}{$\begin{array}{l}\text { Company } \\
\text { Learning \& } \\
\text { Growth }\end{array}$} & EmpCompetency & 0.02228 \\
\hline & EmpSatisfaction & 0.01172 \\
\hline & MgtKnowHow & 0.04758 \\
\hline & TechRD & 0.02970 \\
\hline
\end{tabular}

\begin{tabular}{|l|r|}
\hline \multicolumn{2}{|c|}{ Criteria Priorities Sorted } \\
\hline \multicolumn{1}{|c|}{ Criterion Name } & \multicolumn{1}{c|}{ Priority } \\
\hline Satisfaction & $\mathbf{0 . 1 1 7 3 0}$ \\
\hline AvailabilityPS & $\mathbf{0 . 0 5 6 9 5}$ \\
\hline Profitability & $\mathbf{0 . 0 5 0 3 1}$ \\
\hline MgtKnowHow & $\mathbf{0 . 0 4 7 5 8}$ \\
\hline Agility & $\mathbf{0 . 0 4 3 4 0}$ \\
\hline PriceS & $\mathbf{0 . 0 4 2 6 9}$ \\
\hline Quality & $\mathbf{0 . 0 4 2 4 5}$ \\
\hline CoreFocus & $\mathbf{0 . 0 4 2 3 3}$ \\
\hline IndLeader & $\mathbf{0 . 0 4 0 7 6}$ \\
\hline CostSavings & $\mathbf{0 . 0 4 0 5 4}$ \\
\hline Database & 0.03934 \\
\hline TechRD & 0.02970 \\
\hline InternalControl & 0.02854 \\
\hline EmpCompetency & 0.02228 \\
\hline Certifications & 0.01765 \\
\hline CashFlow & 0.01178 \\
\hline EmpSatisfaction & 0.01172 \\
\hline
\end{tabular}

Table 5 Criteria in the ANP model, ranked by priority. The top 10 are in boldface.

\begin{tabular}{|l|r|r|c|}
\hline \multicolumn{4}{|c|}{ Overall Alternative Rankings - ANP } \\
\hline \multicolumn{1}{|c|}{ Name } & Ideals & Normals & Raw \\
\hline Insourcing & 0.6579 & 0.2650 & 0.0417 \\
\hline Outsourcing & 0.8252 & 0.3323 & 0.0523 \\
\hline SelectOut & 1 & 0.4027 & 0.0634 \\
\hline
\end{tabular}

Table 6. Priorities of strategic options

words, two-way arrows as well as some one-way arrows are used to illustrate the interdependencies (interactions) of criteria within clusters and between clusters.

ANP assists in deriving the global priorities of the criteria by first pairwise comparing them with regard to their BSC perspective and then to all other criteria which they interact with (or have influence on). Next, each normalized comparison matrix is taken to the limit to calculate the local priority of every criterion. In the last step, a super-matrix consisting of all the local-limiting matrices is formed for overall criteria prioritization and alternative ranking. The weighted supermatrix is taken to the limit for the final results. Table 3 shows pairwise comparison results of the four criteria with respect to the Financial Perspective and the derived local priorities of those criteria within the Financial Perspective cluster. In Figure 3, financial indicators such as Profitability and Cost Savings interact with indicators under the other three perspectives. To understand such interaction effects, Table 4 gives example pairwise comparisons of indicators under the Customers Perspective with respect to the financial indicator Profitability. The last row of Table 4 shows the local priorities of the Customers Perspective indicators; these local priorities represent the importance ranking of the indicators with respect to Profitability. Table 5 shows the global 
priorities of all 17 criteria derived by taking the limit of weighted supermatrix of the ANP model. The 10 highest scored criteria are in boldface and are underlined.

The three strategic alternatives are pairwise compared under each of the 17 criteria, and each comparison matrix is used to calculate the local rankings of the alternatives. These local rankings of the alternatives are included in the supermatrix for the final calculation. The composite scores of the alternatives are the overall rankings of the alternatives.

The final synthesized alternative (strategy option) rankings are given in Table 6 . The raw scores are the limiting values of the weighted supermatrix for the alternatives. The Ideals are the raw values divided by their largest member. The Normals are the normalized values (each raw score divided by the total) of the raw scores.

\section{A case example of the model}

To demonstrate the applicability of the ANP-BSC model we empirically address the IT needs of a Pittsburgh-based commercial building contractor that generates approximately $\$ 50$ million in annual revenue. A recent information system problem nearly caused a delay to the bid submission of an important project, which could result in losing a sizeable contract. To ensure quality and on-time bidding document preparation and submission, management of the company was compelled to re-consider streamlining IT functions, where IT outsourcing was one of the options. The authors were provided with the access to key personnel of the company, and were readily accepted for an across-the-board examination. Top executives of the firm, including the owner and CEO of the company, were interviewed to establish alternatives and criteria, to determine the ANP network connections, and to provide the numerical inputs to the base ANP/AHP model. Table 7 gives example interview questions used to derive the first two rows of pairwise comparison results shown in Table 8 .

\subsection{Sensitivity analysis}

To understand how criteria priorities may affect the final outcome of alternative rankings, we conducted a "what-if" analysis in Excel using the method introduced by Saaty (2009). We conduct sensitivity analysis by changing the criteria weights one at a time while holding the relative weights of the other criteria constant. The sensitivity analysis is carried out by applying the model to different scenarios, and examining the situations in which the firm's motivation and concerns toward outsourcing vary. For that purpose, we conducted multiple 15-step sensitivity analyses using all of the seventeen criteria. The results showed that for most of the criteria, when their priority changes, the relative ranking of the three alternative changes very little. Two examples were shown in Figure 2 and 3 below. The only exception was customer Database. When the priority of changes from 0.0001 to 0.9999 , the ranking of Insourcing and Outsourcing reversed at the point when priority of Database was approximately 0.61 (see Figure 4). This was a strong demonstration of the model robustness. Table 9 shows the calculation of alternative scores when changing Database priority from 0.0001 to 0.9999 with an increment of 0.0714 . 


\begin{tabular}{|l|l|l|l|l|l|c|}
\hline $\begin{array}{l}\text { The green shaded cells are the respondents asked of the } \\
\text { questions below. }\end{array}$ & & & & & & reverse \\
\hline $\begin{array}{l}\text { With respect to the goal of maximizing benefits, how much } \\
\text { more important is Costsavings than AccessSkills? }\end{array}$ & 1 & 3 & 5 & 7 & 9 & \\
\hline $\begin{array}{l}\text { With respect to the goal of maximizing benefits, how much } \\
\text { more important is Costsavings than QualitylT? }\end{array}$ & 1 & 3 & 5 & 7 & 9 & \\
\hline $\begin{array}{l}\text { With respect to the goal of maximizing benefits, how much } \\
\text { more important is Costsavings than ResponseTime? }\end{array}$ & 1 & 3 & 5 & 7 & 9 & \\
\hline $\begin{array}{l}\text { With respect to the goal of maximizing benefits, how much } \\
\text { more important is AccessSkills than Quality/T? }\end{array}$ & 1 & 3 & 5 & 7 & 9 & $V$ \\
\hline
\end{tabular}

Table 7. Example interview questions

\begin{tabular}{|l|l|c|c|c|}
\hline \multicolumn{5}{|c|}{ Pairwise Comparison of Benefits Criteria With Respect to the Goal of Maximizing Benefits of IT } \\
Outsourcing \\
\hline & AccessSkills & CostSavings & QualitylT & ResponseTime \\
\hline AccessSkills & 1 & $1 / 7$ & $1 / 3$ & $1 / 4$ \\
\hline CostSavings & 7 & 1 & 3 & 2 \\
\hline QualitylT & 3 & $1 / 3$ & 1 & $1 / 2$ \\
\hline ResponseTime & 4 & $1 / 2$ & 2 & 1 \\
\hline
\end{tabular}

Table 8. Pairwise comparisons resulting from interview process

\begin{tabular}{|r|r|r|r|}
\hline Database Priority & Insourcing & Outsourcing & SelectOut \\
\hline 0.0001 & 0.2573 & 0.3369 & 0.4058 \\
\hline 0.0715 & 0.2631 & 0.3334 & 0.4035 \\
\hline 0.1429 & 0.2689 & 0.3300 & 0.4011 \\
\hline 0.2143 & 0.2747 & 0.3265 & 0.3988 \\
\hline 0.2858 & 0.2805 & 0.3231 & 0.3964 \\
\hline 0.3572 & 0.2863 & 0.3196 & 0.3941 \\
\hline 0.4286 & 0.2921 & 0.3162 & 0.3917 \\
\hline 0.5 & 0.2979 & 0.3127 & 0.3894 \\
\hline 0.5714 & 0.3037 & 0.3093 & 0.3870 \\
\hline 0.6428 & 0.3095 & 0.3058 & 0.3847 \\
\hline 0.7142 & 0.3153 & 0.3024 & 0.3823 \\
\hline 0.7857 & 0.3211 & 0.2989 & 0.3800 \\
\hline 0.8571 & 0.3269 & 0.2955 & 0.3776 \\
\hline 0.9285 & 0.3327 & 0.2920 & 0.3753 \\
\hline 0.9999 & 0.3385 & 0.2886 & 0.3729 \\
\hline
\end{tabular}

Table 9. Alternative scores change as Database priority changes 


\subsection{The recommended strategy}

Using criterion priorities derived from company interviews, selective outsourcing scores highest, with Outsourcing second and Insourcing last. We varied the weights of all criteria between $0.01 \%$ and 99.99\%; all the sensitivity analysis results show that within the entire analysis spectrum, SelectOut ranks the highest. Insourcing is the lowest scored alternative for at least $97.7 \%$ of the analysis spectrum, the only time when Insourcing is ranked higher than outsourcing is when Database priority is over 0.61 . The sensitivity analysis results demonstrate robustness of the proposed model, and are supported by the survey results in Lacity and Willcocks (Larcity \& Willcocks, 2000). Note that Insourcing ranks higher than Outsourcing when Database Security is very high, and Insourcing ranking increases as the priority of InternalControl increases. Both are consistent with common knowledge.

\section{Summary}

In this paper, we showed how the Balanced Scorecard could be operationalized to serve as a basis for strategic IT outsourcing decision making. The balanced scorecard framework captures and relates different perspectives and indicator measures, providing a comprehensive view of the firm for strategic analysis. The Analytical Network Process provides a proven way of eliciting and quantifying the relationships necessary to implement the BSC. The ANP is particularly important for estimating the values of interactions in the BSC model. Using a case study, we demonstrate the practicability of the combined BSC-ANP approach, as well as its ability to improve decision making process when interaction terms are considered.

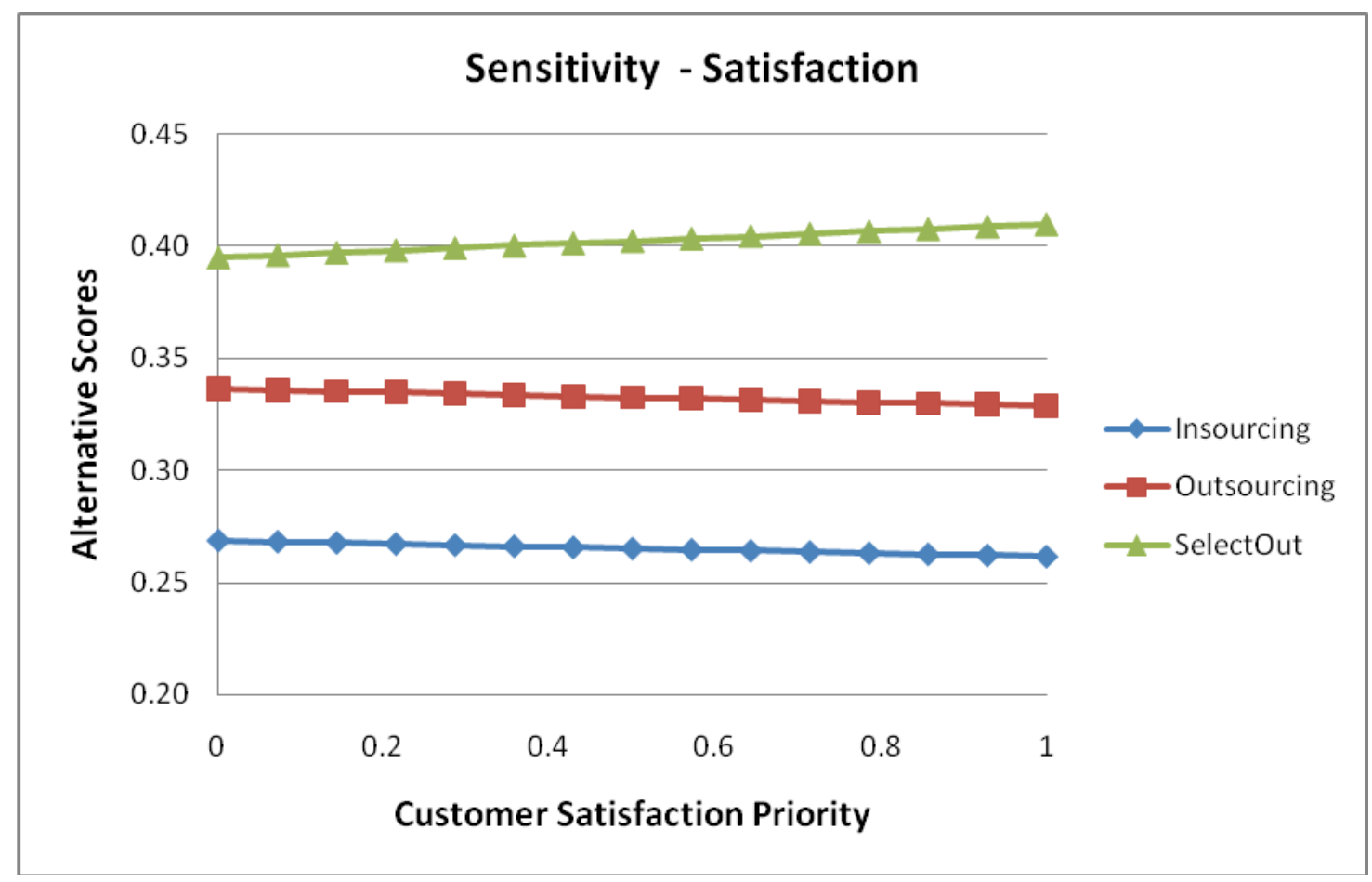

Figure 2. Sensitivity analysis on Customer Satisfaction.

SelectOut shows a slight upward trend when the weight of Customer Satisfaction increases. 


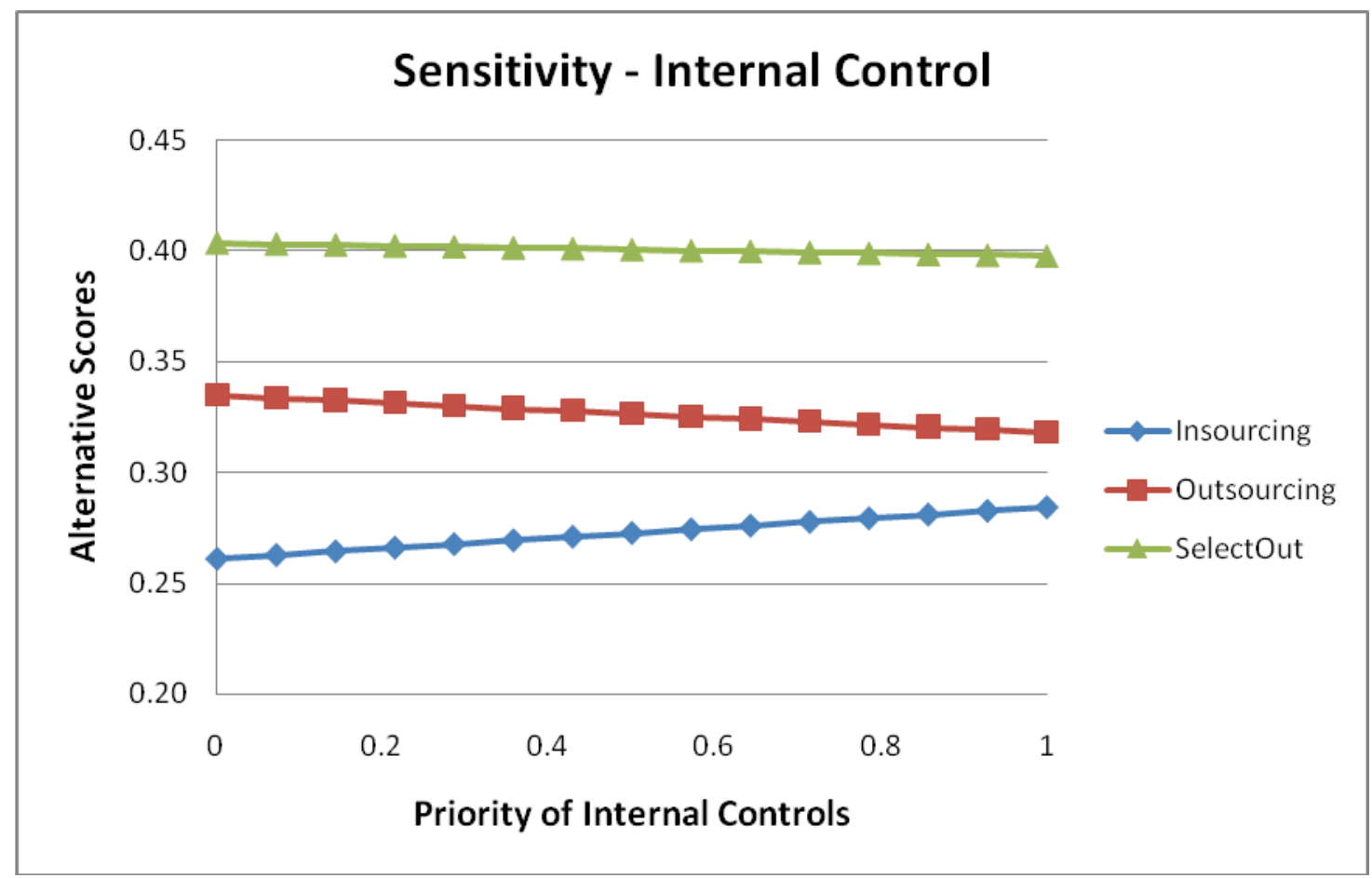

Figure 3: Sensitivity analysis on InternalControl.

Insourcing shows an upward trend as the priority of InternalControl increases.

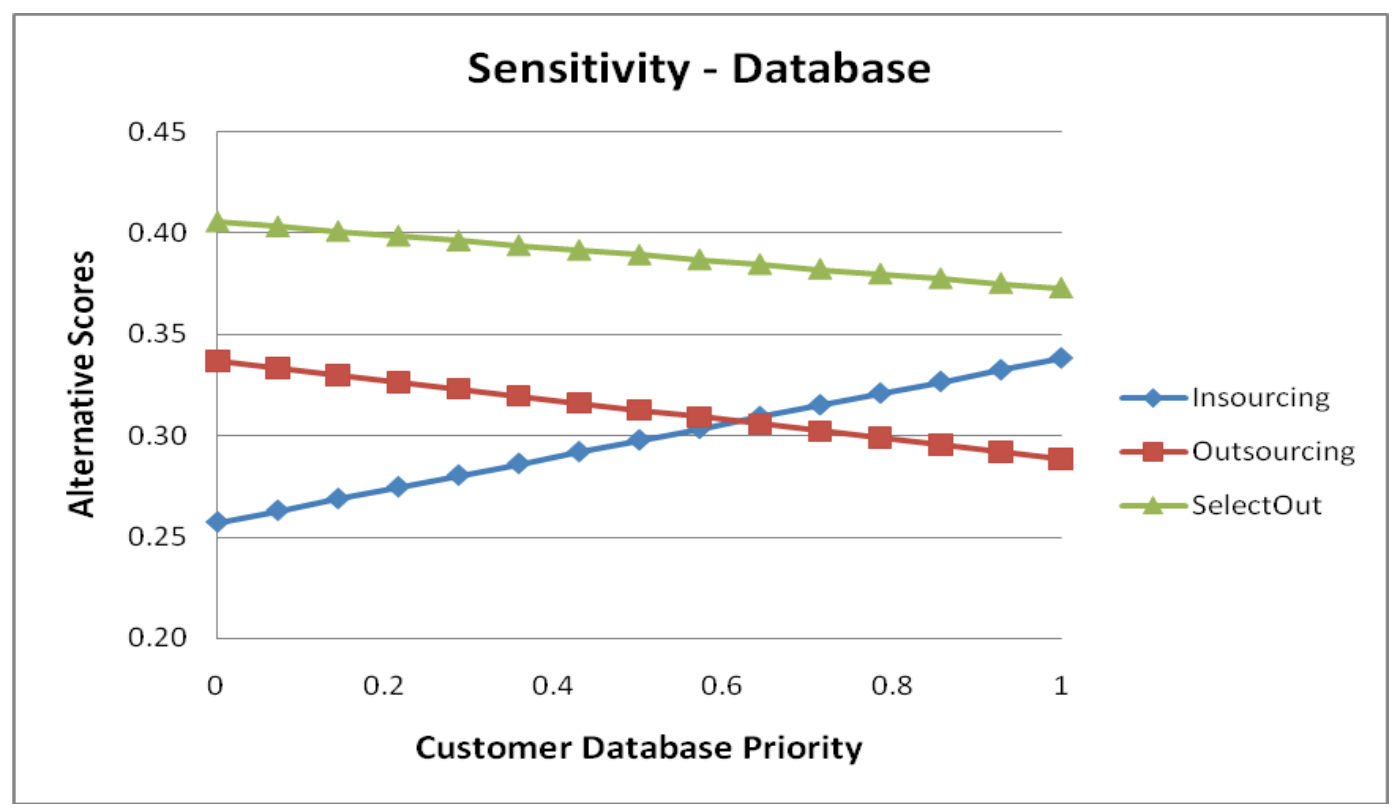

Figure 4. Sensitivity analysis for Customer Database.

The ranks reverse between Insourcing and Outsourcing when Customer Database Security becomes very important 


\section{REFERENCES}

Applegate, L.M., Ibarra, H., \& Ostrofsky, K. (1990). Digital Equipment Corp.: The Kodak outsourcing agreement (B). Harvard Business Review.

Campbell, D., Datar, S., Kulp, S., \& Narayanan, V.G. (2002). Using the Balanced Scorecard as a Control System for Monitoring and Revising Corporate Strategy. Working paper.

Chen, J.-R., Chou, T.-C., \& Lin, Y.-C. (2007). Design and implementation of an ontology-based information technology outsourcing evaluation system using AHP. Int. Journey; Innovation and Learning 4.

Cobbold, I., \& Lawrie, G. (2002a). Classification of Balanced Scorecards based on their intended use. PMA Conference. Boston, USA: 2GC Active Management.

Cobbold, I., \& Lawrie, G. (2002b). The development of the Balanced Scorecard as a strategic management tool. PMA Conference. Boston USA.

Corbett, M.F. (2004). The Outsourcing Revolution: why it makes sense and how to do it right: Dearborn Trade Publishing.

Creative_Decisions_Foundation.(2009). Super Decisions. www.superdecisions.com.

Cullen, S., \& Willcocks, L. (2003). Intelligent IT Outsourcing - Eight Building Blocks to Success: Elsevier.

Domberger, S. ed. (1998). The Contracting Organization: a strategic guide to outsourcing. Oxford: Oxford University Press.

Dong, J., Du, H.S., Lai, K.K., \& Wang, S. (2004). XML-Based Decision Support Systems: Case Study For Portfolio Selection. International Journal of Information Technology and Decision Making 3, 651662.

Francis, J., \& Shipper, K. (1999). Have financial statements lost their relevance? Journal of Accounting Research 37, 319-352.

Hooks, K.L., Kaplan, S.E., \& Schultz, J.J. (1994). Enhancing Communication to Assist in Fraud Prevention and Detection. Auditing: A Journal of Practice and Theory 13, 86-117.

Larcity, M.C., \& Willcocks, L.P. (2000). Survey of IT outsourcing experiences in US and UK organizations (Industry trend and event). Journal of Global Information Management 8, 5-34.

Lee, J.W., \& Kim, S.H. (2000). Using analytic network process and goal programming for interdependent information system project selection. Computers \& Operations Research 27, 367-382.

Lokachari, P.S., \& Mohanarangan, M. (2001). Outsourcing of Information Technology Services: A Decision-Making Framework.

Marc, J.S., \& Wilson, R.L. (1991). Using the analytic hierarchy process and goal programming for information system project selection. Information and Management 20, 333-342. 
Marr, B., \& Neely, A. (2003). Automating your scorecard: The balanced scorecard software report. Cranfield Management Research Institute.

Meade, L., \& Sarkis, J. (1998). Strategic analysis of logistics and supply chain management systems using the analytical network process. Transportation Research E: The Logistics and Transportation Review 34, 201-215.

Nakagawa, T., \& Sekitani, K. (2004). A use of analytic network process for supply chain management. Asia Pacific Management Review 9, 969-998.

Rigby, D.K. (2001). Management tools and techniques: A survey. California Management Review 43.

Saaty, T.L. (1980). Analytic Hierarchy Process - Planning, Priority Setting, Resource Allocation: McGraw-Hill, Inc.

Saaty, T.L. (2001). The Analytic Network Process. Pittsburgh: RWS Publications.

Saaty, T.L. (2005). Theory and Applications of the Analytic Network Process: Decision Making with Benefits, Opportunities, Costs, and Risks. Pittsburgh, PA: RWS Publications.

Saaty, T.L., \& Ozdemir, M. (2004). The Encyclicon: A Dictionary of Decisions with Dependence and Feedback Based on the Analytic Network Process: RWS Publications.

Saaty, T.L., \& Vargas, L.G. (2006). Economic, Political, Social \& Technological Applications of the Analytic Network Process (ANP): Benefits, Opportunities, Costs and Risks. vol. Kluwer Academic Publishers.

Shang, J.S., Tjader, Y., \& Ding, Y. (2004). A unified framework for multicriteria evaluation of transportation projects. IEEE Transactions on Engineering Management 51, 300-313.

Stausberg, J., Lang, H., Obertacke, U., \& Rauhut, F. (2001). Classifications in Routine Use: Lessons from ICD-9 and ICPM in Surgical Practice. Journal of the American Medical Informatics Association 8, 92-100.

Thakkar, J., Deshmukh, S.G., Gupta, A.D., \& Shankar, R. (2007). Development of a balanced scorecard an integrated approach of interpretive structural modeling (ISM) and analytic network process (ANP). International Journal of Productivity and Performance Management 56, 25-59.

Tjader, Y., Shang, J., \& Vargas, L. (2009). Offshore Outsourcing Decision Making: A Policy-Maker's Perspective. Working paper, University of Pittsburgh. 